\title{
Risk of sudden death during sleep in syringomyelia and syringobulbia
}

\author{
Martín A Nogués, Ricardo Gené, Horacio Encabo
}

\begin{abstract}
Clinical, respiratory, and polysomnographic findings in three patients with syringomyelia and syringobulbia who developed severe respiratory complications are described. Neurological examination showed evidence of IXth and $X$ th cranial nerve involvement with dysphagia and dysphonia, but there were no complaints of serious sleep difficulties. Two patients died during sleep and the other was resuscitated during a nap. All patients showed moderate restrictive ventilatory defects with reduced maximal buccal pressures and one also showed a low ventilatory response to $\mathrm{CO}_{2}$ rebreathing. Protracted central, obstructive, and mixed apnoeas and hypopnoeas were commonly observed during sleep. There were no changes in heart rate during these events. A combination of respiratory and cardiovascular mechanisms might have been responsible for the severe complications described.
\end{abstract}

Respiratory abnormalities have been described in patients with syringomyelia and syringobulbia. ${ }^{1-5}$ Several nuclei and pathways known to be involved in the voluntary or automatic regulation of breathing in animals may eventually be damaged by a syrinx, such as the vagal afferent fibres from the lungs to the medulla; the nucleus tractus solitarius; ${ }^{6}$ the inspiratory and expiratory neurons located at the motor dorsal vagus, ambiguus, and tractus solitarius nuclei ${ }^{7}$; the ascending afferents and descending efferents involved in breathing control at the medulla or cervical spinal cord; and the effector motor neurons to the diaphragm and intercostal muscles. ${ }^{8}$ Despite the recognition of respiratory hazards in syringomyelia-syringobulbia patients, breathing abnormalities have so far received scant attention, particularly regarding their potential implication in sudden death.

The integrity of pathways and centres involved in voluntary and automatic breathing may be assessed by functional volume and pressure studies, together with polygraphic recordings during sleep. We describe the clinical and laboratory findings in three patients with advanced syringomyelia and syringobulbia. Respiratory and polysomnographic studies disclosing abnormalities may explain the severe acute complications reported.

\section{Patients and methods}

Case 1

This $\mathbf{5 4}$ year old man first noticed dizziness, dysphagia, and dyspnoea at the age of 37 . A diagnosis of syringobulbia and syringomyelia was made at that time. Though he was treated with radiotherapy, his condition worsened. $\mathrm{He}$ then remained stable for 15 years, after which he noticed progressive weakness of all four limbs. He had been born by an abnormal delivery with forceps, suffering postnatal asphyxia.

On examination in March 1988 his overall appearance was normal, but he had noticeable wasting and weakness of the shoulder girdle. He had an ataxic gait, a left Horner's syndrome, horizontal and vertical nystagmus, definite wasting and weakness of proximal muscles in upper limbs, and arreflexia. He had a spastic paraparesis, with brisk jerks and bilateral extensor plantar responses. Deep sensation was impaired in both hands, and there was an area of dissociated sensory loss from the face down to T5 bilaterally.

An MRI showed atrophy of the right cerebellar hemisphere and a cervical syrinx extending upwards to the lower part of the medulla (fig 1). He denied any sleep difficulties.

He had posterior fossa decompression with laminectomy at $\mathrm{C} 1$ and C2 in June 1988, and an extensive cervical arachnoiditis was found. The floor of the fourth ventricle was also explored, and a syringocysternal catheter was placed. After operation his swallowing difficulties worsened and the left upper limb became weaker. Nine days after surgery the patient had a sudden cardiorespiratory arrest while asleep in hospital and was successfully resuscitated. He received intermittent positive pressure ven-

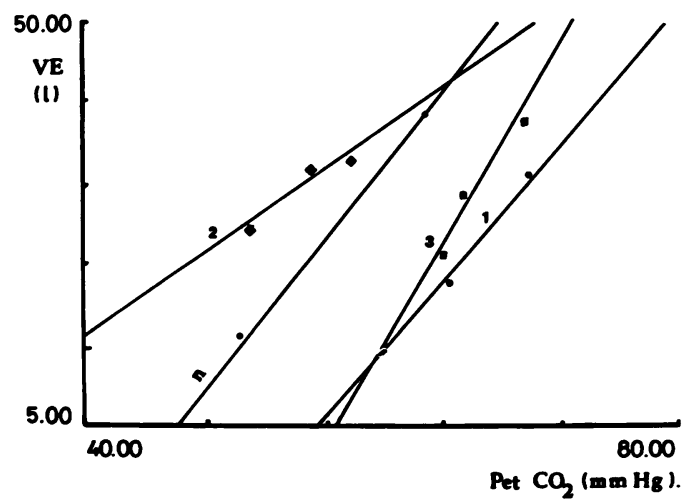

Ventilatory response to $\mathrm{CO}_{2}$ rebreathing: ventilation $/ \mathrm{PCO}_{2}$ curve slopes in the three patients. Mean response in normal subjects given in open circles. 
tilation for a month. He was found dead one morning three months after surgery.

Case 2

This 68 year old man developed wasting and weakness of both hands at the age of 30 . This was followed by progressive loss of pain and temperature sensation over the right upper limb, and later the left, in a cape distribution down to the waist. Over the past 10 years he developed progressive weakness of the lower limbs, severe oscillopsia, dysphagia, and occasional dyspnoea. The diagnosis of syringomyelia was confirmed by myelography. Born by normal delivery, he had suffered meningitis at the age of 11 .

On examination in August 1986 the patient had a short neck and low hair implantation. There was a left Horner's syndrome, marked rotatory nystagmus to the left, wasting of the left sternocleidomastoid muscle, and wasting and fasciculations of the left side of the tongue. There was noticeable bilateral wasting and weakness of proximal and distal upper limb muscles, and reflexes were absent. He had spastic paraparesis, and bilateral extensor plantar responses were elicited. Dissociated sensory loss down to T4 was found. Vibration sense was impaired in all four limbs, but position sense was normal throughout. Although he never complained of sleep-wake difficulties, over the past 10 years relatives had noticed irregular breathing during sleep, such as respiratory pauses followed by strenuous snoring. In December 1988, the patient's wife reported he had stopped breathing altogether in the course of an afternoon nap, and became cyanotic. She aroused him violently and started cardiopulmonary resuscitation. After several minutes he began to breathe normally, showing a decerebrate posture for several more minutes. He was admitted to hospital and recovered fully. The patient refused to be investigated by MRI.

Case 3

This 38 year old man first noticed progressive wasting and weakness of both arms at the age of 25. A year later his legs were also weak and walking had become difficult. His medical history was unremarkable apart from his birth after a prolonged and traumatic labour.

In 1975 a myelogram showed widening of the cervical and thoracic spinal cord. A CT scan showed moderate hydrocephalus with considerable dilatation of the fourth ventricle; a ventriculoperitoneal shunt was placed in December 1979, resulting in a slight improvement. In 1986, after a fall, his neurological condition deteriorated progressively. An MRI showed a normal brainstem and cerebellum with no evidence of cerebellar tonsillar herniation. The fourth ventricle was of normal size and location. The cervical spinal cord was noticeably atrophic from the level of the foramen magnum downwards, and a collapsed syrinx extended from the 4 th ventricle down to T5. There was no radiological evidence of a lesion in the medulla. The patient had a T5 laminectomy, syringotomy, and placement of a syringoperitoneal shunt. Postoperatively, he recovered gradually, with some improvement of the spastic tone.

On examination the patient had bilateral Horner's syndrome and considerable nystagmus in all directions. There was weakness of the muscles innervated by the IXth, Xth, and XIth cranial nerves. Both upper limbs and shoulder girdles showed definite muscle wasting with reduced muscle tone and claw-like deformities of both hands. His upper limbs were areflexic. There was severe bilateral spasticity with hyperreflexia of the lower limbs, ankle clonus, and bilateral extensor plantar responses. Sensory testing disclosed an appreciable dissociated loss, mainly in a right hemicape distribution. Overall, he was severely disabled with hardly any useful function of his hands and he could walk only with assistance.

Over the past two years he had had occasional respiratory difficulties at night, waking up suddenly with breathlessness. Relatives were well aware of these episodes, which were worse after heavy meals or alcohol intake. They turned him over and woke him up. In November 1988 the patient went to sleep after a large meal, waking up with shortness of breath. He sat up in bed, recovered within a few minutes, fell asleep again, and was found dead one hour later.

\section{Pulmonary function tests}

The following variables were determined: flowvolume curves using a Fleisch pneumotach; forced vital capacity (FVC); forced expiratory volume at one second $\left(\mathrm{FEV}_{1}\right) ; \mathrm{FEV}_{1} / \mathrm{FVC}$ ratio; flow expiratory peak; and instantaneous flows at $25 \%, 50 \%$, and $75 \%$ FVC. Expiratory muscle endurance was estimated from the values of maximal voluntary ventilation during 12 seconds. Respiratory muscle force was estimated from maximal inspiratory buccal pressure (PiMax) measured at total lung capacity and maximal expiratory buccal pressure (PeMax) measured from residual volume. Values obtained were compared with normal control values from our own laboratory. ${ }^{9}$

Arterial blood gases were determined from a sample obtained by brachial puncture while the patients were breathing room air. Respiratory centre output was then evaluated by means of the response to $\mathrm{CO}_{2}$ rebreathing, with a Collins spirometer containing a volume equal to the subject's vital capacity plus one litre of the mixed gases containing $7 \% \mathrm{CO}_{2}$ and $93 \% \mathrm{O}_{2}$ (hyperoxygen rebreathing). The end tidal $\mathrm{PCO}_{2}\left(\mathrm{PECO}_{2}\right)$ was measured with an IL infrared $\mathrm{CO}_{2}$ analyser. $\mathrm{A} \mathrm{CO}_{2}$ response curve was plotted over successive intervals of half a minute against $\mathrm{PECO}_{2}$ at their midpoints. Slopes of response curves for ventilation $/ \mathrm{PECO}_{2}$ were calculated with a linear regression analysis. The mean value for normal subjects was $2.51 / \mathrm{mm} \mathrm{Hg}$. Values below 1.0 $1 / \mathrm{mm} \mathrm{Hg}$ were considered abnormal. During the rebreathing test in patient 1 , the occlusion pressure at $0 \cdot 1$ seconds was evaluated by using a balloon inflated during expiration (without the subject's knowledge) and measured $0 \cdot 1$ 
seconds after the start of the next inspiration. All data were recorded by a 2600 Gould polygraph at a paper speed of $50 \mathrm{~mm} / \mathrm{s}$. The day after the pulmonary function studies were performed the subjects were investigated with polysomnography.

\section{Polysomnography}

Patients were studied for one night in a quiet, darkened, sound attenuated room. Routine polysomnographic techniques were used. ${ }^{1011}$ Conventional leads were used for EEG, EOG, EMG (chin and tibialis anterior muscles), and EKG recordings.

Respiratory movements were transduced to pressure changes with rubber bellows placed at the maximal excursion abdominal site (Phipps and Bird pneumograph and Grass PTT5 transducer). EMG intercostal activity was also recorded with surface electrodes. Airflow was monitored by means of nasal and oral thermistors and snoring by a microphone.

The study was repeated in patients 2 and 3 two years later. On the second occasion, and in patient 1 , oxygen saturation was monitored by means of an ear oximeter (Ohmeda Biox 3700), while a Model 78 D Grass polygraph was used throughout. Recordings were made at a chart speed of $15 \mathrm{~mm} / \mathrm{s}$, which allowed a one page scoring epoch of 20 seconds.

\section{Results}

Pulmonary function studies

As shown in table 1 , patients 1 and 3 had a reduced respiratory rate, ranging from 7 to 9 breaths per minute. Patient 1 had a prolonged inspiratory time as well. Overall, patients showed moderate restrictive ventilatory incapacity with reduced maximal buccal pressures. Arterial blood gases at rest showed no evidence of $\mathrm{CO}_{2}$ retention, and two of the three patients had mild hypoxaemia. Ventilatory response to $\mathrm{CO}_{2}$ rebreathing was normal in patient 3, abnormally reduced in patient 2 , and at the lower normal limit in patient 1 (fig 1 ).

Patient 1, who had an abnormally low respiratory rate at rest, showed only a slight rate increase during $\mathrm{CO}_{2}$ rebreathing, ranging from eight to 12 respirations per minute. There were no important changes in heart rate during $\mathrm{CO}_{2}$ rebreathing in any of the patients.

\section{Polysomnography}

All three patients showed low sleep efficiency (table 2). Sleep was frequently interrupted by

Table 1 Results of pulmonary function tests

\begin{tabular}{|c|c|c|c|c|c|c|c|c|c|}
\hline \multirow[b]{2}{*}{ Test or variable } & \multicolumn{3}{|l|}{ Case 1} & \multicolumn{3}{|c|}{ Case 2} & \multicolumn{3}{|l|}{ Case 3} \\
\hline & $A$ & $N$ & $\%$ & $A$ & $N$ & $\%$ & $A$ & $N$ & $\%$ \\
\hline $\begin{array}{l}\text { Respiratory rate (breaths/min) } \\
\text { FVC (\%) } \\
\text { FEV (\%) } \\
\text { FEV /FVC (\%) } \\
\text { PiMax (\%) } \\
\text { PeMax (\%) } \\
\mathrm{PaO}_{2}(\mathrm{mmHg}) \\
\mathrm{PaCO}_{2}(\mathrm{mmHg})\end{array}$ & $\begin{array}{r}7 \cdot 0 \\
2 \cdot 6 \\
2 \cdot 0 \\
0 \cdot 8 \\
88 \cdot 0 \\
114 \cdot 0 \\
67 \cdot 7 \\
43 \cdot 1\end{array}$ & $\begin{array}{r}4 \cdot 1 \\
3 \cdot 2 \\
0 \cdot 8 \\
123 \cdot 0 \\
157 \cdot 0\end{array}$ & $\begin{array}{l}62 \cdot 0 \\
64 \cdot 0 \\
\\
71 \cdot 0 \\
58 \cdot 0\end{array}$ & $\begin{array}{r}18 \cdot 0 \\
1.9 \\
1 \cdot 6 \\
0 \cdot 8 \\
59 \cdot 0 \\
88 \cdot 0 \\
68 \cdot 0 \\
36 \cdot 7\end{array}$ & $\begin{array}{r}3 \cdot 1 \\
2.3 \\
0.8 \\
123.0 \\
157.0\end{array}$ & $\begin{array}{l}62 \cdot 0 \\
67 \cdot 0 \\
\\
48 \cdot 0 \\
56 \cdot 0\end{array}$ & $\begin{array}{r}9 \cdot 0 \\
2 \cdot 8 \\
2 \cdot 2 \\
0 \cdot 8 \\
72 \cdot 5 \\
62 \cdot 5 \\
77 \cdot 5 \\
33 \cdot 5\end{array}$ & $\begin{array}{r}5.6 \\
4.6 \\
0.8 \\
123.0 \\
157 \cdot 0\end{array}$ & $\begin{array}{r}50 \cdot 0 \\
48 \cdot 0 \\
\\
59 \cdot 0 \\
53 \cdot 0\end{array}$ \\
\hline $\begin{array}{l}C O_{2} \text { rebreathing: } \\
\text { VE/PECO } \\
\mathrm{PO} .1 / \mathrm{PECO}_{2}\end{array}$ & $\begin{array}{l}1.89 \\
0.50\end{array}$ & $\begin{array}{l}3.20 \\
0.50\end{array}$ & $\begin{array}{l}1.78 \\
0.46\end{array}$ & $1^{1 \cdot 0}$ & $-^{3 \cdot 2}$ & & $\underline{-}^{2 \cdot 76}$ & $-^{3 \cdot 2}$ & \\
\hline
\end{tabular}

$A=$ Absolute value

$\mathbf{N}=$ Normal value

$\%=$ Percentage of predictive value

FVC = forced vital capacity; FEV $_{1}=$ forced expiratory volume at one second; PiMax = maximal buccal inspiratory pressure as percentage of predicted value; $\mathrm{PeMax}=$ maximal buccal expiratory pressure as percentage of predicted value; $\mathrm{VE} / \mathrm{PECO}=\mathrm{Pentila}$

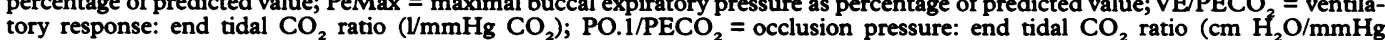
$\stackrel{\mathrm{CO}}{\mathrm{C}})_{2}$.

Table 2 Polysomnographic findings

\begin{tabular}{|c|c|c|c|c|c|}
\hline & \multirow{2}{*}{$\frac{\text { Case } 1}{1 \text { 1st study }}$} & \multicolumn{2}{|l|}{ Case 2} & \multicolumn{2}{|l|}{ Case 3} \\
\hline & & $\begin{array}{l}\text { 1st study } \\
(20 \text { Sept 86) }\end{array}$ & $\begin{array}{l}\text { 2nd study } \\
\text { (18 May 88) }\end{array}$ & $\begin{array}{l}\text { 1st study } \\
\text { (1 Aug 86) }\end{array}$ & $\begin{array}{l}\text { 2nd study } \\
\text { (7 Sept 88) }\end{array}$ \\
\hline $\begin{array}{l}\text { Total recording time (min) } \\
\text { Total sleep time (min) } \\
\text { Sleep efficiency }{ }^{\star} \\
\text { Sleep latency (min) } \\
\text { Waking after onset of sleep (min) } \\
\text { Stage } 1 \text { (\%) } \\
\text { Stage } 2(\%) \\
\text { Stage } 3+4(\%) \\
\text { REM stage (\%) } \\
\text { REM latency (min) } \\
\text { No of awakenings } \\
\text { No of central apnoeas (maximal duration in secs) } \\
\text { No of obstructive and mixed apnoeas (maximal duration in secs) } \\
\text { No of hypopnoeas (maximal duration in secs) } \\
\text { Total no of apnoeas and hypopnoeas (mean duration in secs) } \\
\text { Apnoea + hypopnoea indext } \\
\text { Minimum oxygen saturation (\%) } \\
\text { Bradycardia during apnoeas } \\
\text { Periodic leg movements }\end{array}$ & $\begin{array}{l}482 \\
262 \\
0 \cdot 54 \\
17 \\
203 \\
9 \cdot 2 \\
32 \cdot 6 \\
14 \cdot 6 \\
324 \\
38 \\
34(25) \\
13(20) \\
47(13) \\
10 \cdot 7 \\
83 \\
+\end{array}$ & $\begin{array}{c}298 \\
220 \\
0 \cdot 73 \\
1 \\
75 \\
1 \cdot 3 \\
46 \cdot 5 \\
4 \cdot 4 \\
22 \cdot 4 \\
57 \\
25 \\
18(30) \\
42(55) \\
4(35) \\
64(19) \\
17 \cdot 4\end{array}$ & $\begin{array}{l}352 \\
221 \\
0 \cdot 63 \\
19 \\
87 \\
3 \cdot 7 \\
46 \cdot 4 \\
21 \cdot 7 \\
94 \\
14 \\
2(10) \\
70(120) \\
72(41) \\
19 \cdot 5 \\
77 \\
-\end{array}$ & $\begin{array}{c}322 \\
178 \\
0 \cdot 55 \\
54 \\
47 \\
6 \cdot 2 \\
61 \cdot 8 \\
4 \cdot 9 \\
6 \cdot 3 \\
118 \\
98 \\
104(40) \\
36(160) \\
21(60) \\
161(28) \\
54 \cdot 2\end{array}$ & $\begin{array}{c}292 \\
180 \\
0 \cdot 61 \\
30 \\
52 \\
9 \cdot 5 \\
59 \cdot 4 \\
8 \cdot 7 \\
133 \\
131 \\
101(165) \\
5(45) \\
71(170) \\
177(37) \\
58 \cdot 9 \\
<50 \\
-\quad \\
-\end{array}$ \\
\hline
\end{tabular}

*Sleep efficiency: $\frac{\text { total sleep time }}{\text { total recording time }}$.

†Apnoea + hypopnoea index: $\frac{\text { total number of apnoeas }+ \text { hypopnoeas }}{\text { total sleep time in minutes }} \times 60$ 
respiratory events or periodic leg movements, or both. The number of awakenings (arousals lasting at least 10 seconds) and the time to waking after onset of sleep were increased in all studies. Sleep latency was prolonged only in patient 3. Delta sleep (stages 3 and 4) was reduced or absent in the three patients and the REM stage was of brief duration in patients 1 and 3.

Respiration during sleep was disturbed, as shown by the apnoea plus hypopnoea index, which proved higher in subjects 2 and 3 . There were frequent central apnoeas, obstructive apnoeas, and mixed apnoeas, as well as hypopnoeas. On occasion, apnoeas and hypopnoeas were extremely long lasting and associated with low oxygen saturation values, but there was no evidence of concomitant bradycardia.

The second study in patients 2 and 3 showed an increase in the absolute number, mean duration, and maximal duration of apnoeas and hypopnoeas. The longest event recorded lasted 170 seconds (in the second study in patient 3 ). In the second study central and obstructive apnoeas decreased in patient 2, though the number of hypopnoeas increased considerably. Central apnoeas lasting 30-40 seconds were observed in both studies while patient 3 was awake. Patients 1 and 3 also showed a very low respiratory rate (7-9 breaths/minute), and patient 1 had a long inspiratory time (6-10 seconds).

\section{Discussion}

All three patients who had syringomyeliasyringobulbia and severe cardiorespiratory complications had clinical involvement of the cervical spinal cord and medulla, the critical structures for respiratory controls. Abnormalities of respiration in syringomyelia-syringobulbia patients have occasionally been described previously. Ventilatory centre insensitivity to $\mathrm{CO}_{2}$ has been reported in patients with syringomyelia or Chiari type 1 malformation who developed respiratory symptoms. ${ }^{17}$ Insensitivity to hypoxia with a relatively normal response to $\mathrm{CO}_{2}$ was also observed in a patient with a Chiari malformation and syringomyelia. ${ }^{\circ}$ Bilateral weakness of the diaphragm and isolated central respiratory failure have been described in syringomyelia and Chiari type 1 malformation. ${ }^{28}$ Cases of obstructive sleep apnoea have also been reported. ${ }^{3-5}$ Ours is the first study in which respiratory abnormalities were documented by functional respiratory studies and polysomnography before the occurrence of respiratory arrest or sudden death. Furthermore, the recordings have detected abnormalities of heart rate during sleep and low respiratory rates and central apnoeas during wakefulness.

Respiratory functional studies showed that ventilatory mechanisms were affected to a variable degree in these patients, who had in common a pronounced wasting and weakness of intercostal and neck muscles. Nevertheless, there was no clinical evidence of diaphragm weakness. Dyspnoea in two patients was probably due to muscle weakness since buccal pressures were abnormal in all three patients. Maximal buccal pressures are useful in assessing the strength of respiratory muscles: they are easily measured and more sensitive than clinical examination in detecting muscle weakness. Patients 1 and 2 had mild restriction with abnormal responses to $\mathrm{CO}_{2}$, whereas patient 3 had severe restriction and normal response to $\mathrm{CO}_{2}$ rebreathing while awake. Such abnormalities in mechanics may worsen during sleep, leading to more severe ventilatory difficulties, as has already been shown in other conditions, including chronic obstructive pulmonary disease, interstitial lung disease, and scoliosis. ${ }^{12}$

Obstructive, mixed, and central apnoeas were found in all three patients, and the apnoea plus hypopnoea index exceeded the usually accepted normal limit of five events per hour. ${ }^{11}$

Several factors, such as weakness of pharyngeal and laryngeal dilator muscles supplied by pontomedullary cranial nerve nuclei ${ }^{13}$ predisposed these patients to obstructive sleep apnoeas. Our patients had clinical involvement of the IXth and Xth cranial nerves, as in another case previously reported, in which obstructive sleep apnoea was attributed to damage to the ambiguus and hypoglossal nuclei by a syrinx found at necropsy.

The mechanism of central apnoeas in syringomyelia patients is probably related to compression of descending and ascending afferent pathways in the anterolateral region of the cervical spinal cord by the syrinx. A similar mechanism has been suggested to explain central sleep apnoea after percutaneous cordotomy. ${ }^{14}$ Damage to medullary structures may also contribute to this, ${ }^{1516}$ and explain moreover the low respiratory rate found in patients 1 and 3, whether asleep or awake. In patient 2, basilar impression and a Chiari anomaly may also have had a role in the occurrence of these complications. ${ }^{1718}$

The increase in the total number, mean, and maximal duration of apnoeas and hypopnoeas in the second study in patients 2 and 3 suggests deterioration of sleep architecture, most likely due to progression of the disease.

Although patients made no complaints of serious sleep difficulties, relatives were well aware of nocturnal breathing irregularities. Reduced sleep efficiency and increased time to waking after onset of sleep were produced by frequent arousals or awakenings associated with respiratory events or periodic leg movements. The paucity of symptoms of sleep disturbance was in striking contrast to the abnormalities found at polysomnography. Patients denied experiencing excessive daytime sleepiness, repeated nocturnal awakenings, restless sleep, insomnia, or morning headache.

All three patients were at risk of sudden death during sleep. Patients 1 and 3 actually died and patient 2 was resuscitated. These syringobulbia-syringomyelia patients apparently suffered a respiratory arrest while asleep similar to those leading to death in cases of Shy-Drager syndrome, primary cerebral 
involvement, or neurosurgical lesions. ${ }^{141920}$ The concurrence of long lasting apnoeas and hypopnoeas, absence of associated bradycardia or tachycardia, extremely low respiratory rate, and prolonged inspiratory effort point to loss of automatic respiratory regulation during sleep.

In all likelihood, compromise of cardiovascular reflexes contributed to the risk of sudden death in these patients with syringomyelia or syringobulbia. Subclinical involvement of baroreceptor and vagal cardiovascular reflexes are common in syringobulbia patients, particularly in those with clinical evidence of IXth and Xth cranial nerve impairment. ${ }^{21}$ Even though autonomic tests were not undertaken, the constant absence of bradycardia during the apnoeas suggests vagal dysfunction.

In conclusion, our findings emphasise the importance of periodic functional respiratory and polysomonographic studies in patients with syringomyelia or syringobulbia. These studies may indicate the need for nocturnal assisted mechanical ventilation in those patients at a greater risk of sudden death.

1 Campbell EJM. Respiratory failure. BMf 1965;i:1451-60. 2 Bullock R, Todd NV, Easton J, Hadley D. Isolated central respiratory failure due to syringomyelia and ArnoldChiari malformation. BMF 1988;297:1448-9.

3 Haponik EF, Givens E, Angelo J. Syringobulbia-myelia with obstructive sleep apnoea. Neurology 1983;33:1046-9.

4 Adelman S, Dinner DS, Goren H, Little J, Nickerson P Obstructive sleep apnoea in association with posterior fossa neurologic disease. Arch Neurol 1984;41:509-10.

5 Encabo H, Gené R, Nogués MA. Polysomnographic findings in syringomyelia and syringobulbia. Sleep Res 1987;16:474

6 Bokinsky GE, Hudson LD, Weil JV. Impaired peripheral chemosensitivity and acute respiratory failure in ArnoldChiari malformation and syringomyelia. New $\mathcal{f}$ Engl Med 1973;288:947-8.

7 Rodman T, Resnick M, Berkowitz RD, Fennelly JF, Olivia J. Alveolar hypoventilation due to involvement of the respiratory center by obscure disease of the central nervous system. $A m \tilde{F} \mathrm{Med}$ 1962;32:208-17.

8 Nogués MA, Gené R. Diaphragm weakness and syringomyelia. $\mathcal{f}$ Royal Soc Med 1988;81:59.

9 Gené R, Caneva J, Volkman S, Mazzei JA. Detección de valores normales de presiones bucales máximas en valores normales de presion
adultos. Medicina 1988;48:663.

10 Carskadon MA. Basics for polygraphic monitoring of sleep. In: Guilleminault $\mathrm{C}$, ed. Sleeping and waking disorders: indications and techniques. Menlo Park, California: Addison-Wesley, 1982:1-16.

11 Keenan Bornstein S. Respiratory monitoring during sleep: Polysomnography. In: Guilleminault C, ed. Sleeping and waking disorders: indications and techniques. Menlo Park, California: Addison-Wesley, 1982:183-212.

12 Tatsuni K, Kimura H, Kunitomo F, Kuriyama T, Honda Y. Arterial oxygen desaturation during sleep in interstitial pulmonary disease. Chest 1989;95:962-7.

13 Remmers J, DeGroot W, Sauerland E. Pathogenesis of upper airway occlusion during sleep. $f$ Appl Physiol upper airway.

14 Krieger AJ. Sleep apnoea produced by cervical cordotomy and other neurological lesions in man. In: Guilleminault and other neurological lesions in man. In: Guilleminault C, Dement W, eds.
Liss, 1978:273-94.

15 Cherniack NS. Respiratory dysrhythmias during sleep. N Engl f Med 1981;105:325-30.

16 Önal E. Central sleep apnea. Seminars in Respiratory Medicine 1988;9:547-53.

17 List CF. Neurologic syndromes accompanying developmental anomalies of the occipital bone, atlas and axis. Arch Neurol Psychiatry 1941;45:577-616.

18 Fish DR, Howard RS, Wiles CM, Symon L. Respiratory arrest: a complication of cerebellar ectopia in adults. f Neurol Neurosurg Psychiatry 1988;51:714.

19 Lugaresi E, Coccagna G, Mantovani M. Hypersomnia with periodic apneas. New York: Spectrum, 1978:104-5.

20 Briskin JG, Lehrman KI, Guilleminault C. Shy-Drager syndrome and sleep apnea. In: Guilleminault C, Dement W, eds. Sleep apnoea syndromes. New York: Liss, 1978: 317-22.

21 Nogués MA, Newman PK, Male VJ, Foster JB. Cardiovascular reflexes in syringomyelia. Brain 1982;105:835-49. 